\title{
A Movable Fog-Haze Boundary Layer Conceptual Model Over Jianghuai Area, China
}

\author{
Duanyang Liu ${ }^{1,2,3 *}$, Wenlian Yan ${ }^{1,4 *}$, Junlong Qian ${ }^{1,5}$, Mei Liu ${ }^{1,4}$, Zida Wang $^{6}$, Muning Cheng ${ }^{3}$ \\ and Huaqing Peng ${ }^{5}$
}

${ }^{1}$ Key Laboratory of Transportation Meteorology, China Meteorological Administration (CMA), Nanjing, China, ${ }^{2}$ Nanjing Joint Institute for Atmospheric Sciences, Nanjing, China, ${ }^{3}$ Collaborative Innovation Center of Atmospheric Environment and Equipment Technology, Jiangsu Key Laboratory of Atmospheric Environment Monitoring and Pollution Control (AEMPC), Nanjing University of Information Science \& Technology, Nanjing, China, ${ }^{4}$ Meteorological Observatory of Jiangsu Province, Nanjing, China, ${ }^{5}$ Wuxi Meteorological Observatory of Jiangsu Province, Wuxi, China, ${ }^{6}$ Department of Integrated Traffic Information and Control Engineering, School of Transportation Engineering, Tongji University, Shanghai, China

OPEN ACCESS

Edited by:

Lijuan Shen,

University of Toronto, Canada

Reviewed by:

Mengmeng Li,

Nanjing University, China

Gui Hai Lin,

China Meteorological Administration,

China

*Correspondence:

Duanyang Liu

liuduanyang@cma.gov.cn

Wenlian Yan

yike-112@163.com

Specialty section:

This article was submitted to

Atmosphere and Climate,

a section of the journal

Frontiers in Environmental Science

Received: 26 October 2021

Accepted: 16 November 2021

Published: 30 November 2021

Citation:

Liu D, Yan W, Qian J, Liu M, Wang Z, Cheng $M$ and Peng $H$ (2021) $A$

Movable Fog-Haze Boundary Layer Conceptual Model Over Jianghuai

Area, China.

Front. Environ. Sci. 9:802316. doi: $10.3389 /$ fenvs.2021.802316
The Jianghuai area is an "important" region not only for its local pollutant accumulation but the belt for pollutant transportation between North China and the Yangtze River Delta during the winter half of the year (often from October to next February). In this study, a movable boundary layer conceptual model for the Jianghuai area in the winter half of the year is established based on the analyses of characteristics of atmospheric circulations and boundary layer dynamic conditions. This conceptual model can well explain the causes of air quality change and frequent fog-haze episodes. Variations of the intensity and range of the cold and warm fronts in the Jianghuai area in the winter half of the year lead to form a movable boundary in this area. When the southerly wind is strong, or affected by strong cold air mass, the air quality in the Jianghuai area may be excellent with a low air pollution index; Two atmospheric circulations provide favorable conditions for the fog-haze formation and maintenance in Jianghuai area: 1) When the shallow weak cold air mass is below the deep moist warm air mass, a stable temperature inversion occurs. The pollutants are transported to the Jianghuai area by the weak cold air mass, and local emissions also accumulate. As a result, a severe air pollution episode appears. 2) When the northerly cold air mass is as intense as the southerly moist warm air mass, the pollutants transported from North China as well as local emissions will continuously accumulate in the study area, which may lead to more severe air pollution. This conceptual model can help us analyze atmospheric diffusion capacity, and benefit the forecast and early warning of airflow stagnation area and fog-haze episode.

Keywords: heavy air pollution, atmospheric circulation, atmospheric boundary layer, movable boundary layer conceptual model, jianghuai area, China

\section{INTRODUCTION}

Regional air quality is a rising concern in East China in recent years, many severe air pollutions were recorded in East China (Dai et al., 2020; Gu et al., 2020; Shi et al., 2020; Sun et al., 2020; Wang et al., 2021), Beijing-Tianjin-Hebei region (Liu et al., 2019a; Li et al., 2019, 2020; Lv et al., 2020) and the Pearl River Delta (Wu et al., 2013; Li et al., 2018; Dai et al., 2019), due to rapid developments of 
economy and urbanization in these regions. The rapid and varied industrial development, the use of coal for power generation, and the increasing number of vehicles on the roads have increased the emission of pollutants in the region, especially particulate matter (PM) and its precursors. Stable circulation, stable atmospheric stratification, and high humidity are all important factors for the formation and aggravation of haze pollution (Ding and Liu, 2014; Mu and Zhang, 2014; Liu et al., 2019b). Zhang et al. (2014) reported that meteorological factors could explain more than $2 / 3$ of the variance of fog-haze diurnal variation.

East China is a region with frequent fog and haze (Chen et al., 2021; Wang et al., 2020; Zhang et al., 2018; Zong et al., 2020). Local emissions, pollutants transported from the North China Plain, and boundary layer change can all affect the intensity and duration of the fog-haze episode (Liang et al., 2017; Wang et al., 2016; Yu et al., 2016). The atmosphere boundary layer conditions in the Jianghuai area, which covers Jiangsu and Anhui provinces in this article, can affect not only local pollutant concentration but also pollutant transportation between North China and the Yangtze River Delta (Dai et al., 2020; Gu et al., 2020; Liu et al., 2018a; Liu et al., 2018b; Peng et al., 2016; Shen et al., 2021a; Shen et al., 2021b; Xie et al., 2021; Zhou et al., 2021).

Conceptual models for different types of weather will help us analyze the synoptic situations and boundary layer features, and improve forecasting and early warning and understanding the weather processes (Pal, 2016; Wojtal, et al., 2011). Over the past decade, different researchers have developed conceptual models about different weather phenomena (Lohou et al., 2020; Toledo et al., 2021), for example, Toledo et al. (2021) presents a new conceptual model for adiabatic fog, Lohou et al. (2020) build a conceptual model of diurnal cycle of low-level stratiform clouds over southern West Africa.

Fog-haze weather researches are all aspects, the research on conceptual models of weather is very systematic, which contributes to a comprehensive understanding of different types of weather (Ding et al., 2017; Wu et al., 2017). Wu et al. (2017) give a conceptual diagram for the formation mechanism of persistent haze pollution events in North China. When a severe persistent haze event occurs, North China is dominated by zonal westerly airflow or by northwesterly airflow in the mid-upper troposphere.

The purpose of this study is to analysis the relationship between synoptic weather patterns and the boundaries layers in the Jianghuai area, China and in comparison with the North China Plain (Xu et al., 2012; Jiang et al., 2015; Li et al., 2015; Ding et al., 2017; Meng et al., 2017) and the Pearl River Delta, China (Fan et al., 2005, Fan et al., 2006). To explore air quality change and frequent fog-haze episodes in the Jianghuai area, China during the winter half of the year, characteristics of atmospheric circulation and BL dynamic and thermal conditions are analyzed. A movable boundaries layers conceptual model approach using synoptic analysis methods is proposed here to investigate the good air quality synoptic situations, and the heavy air pollution weather synoptic background.

The remainder of this paper is organized as follows: The study area, data, and methods are described in Section 2. In Section 3 we summarize the atmospheric circulation and boundary layers' dynamic conditions on fog-haze days. A movable BL conceptual
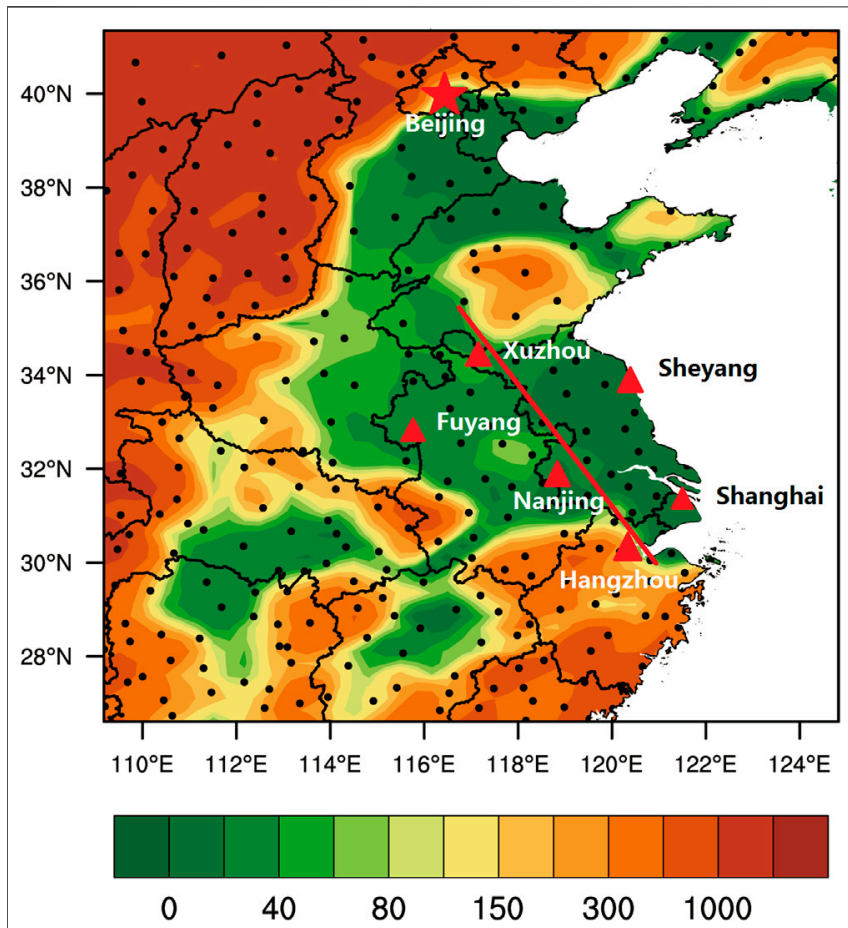

FIGURE 1 | The geographical environment of the Jianghuai area (where the red triangles region), referring to as Jiangsu and Anhui provinces in this article. The red triangles represent the primary meteorological stations (Xuzhou (XZ), Sheyang (SY), Fuyang (FY), Nanjing (NJ), Shanghai (SH), Hangzhou $(\mathrm{HZ})$ ) in the Jianghuai area, the red line is used to analyze the wind field and the conceptual model, and the black dots are the other stations of CMA. The color is the altitude.

model is established in Section 4. Finally, summary and conclusions are presented in Section 5.

\section{THE STUDY AREA, DATA, AND METHOD}

\section{Study Area}

The geographical environment of the Jianghuai area referring to as Jiangsu and Anhui provinces in this article (Figure 1). In terms of physical geography, the Jianghuai area located in the transitional area from the subtropics to the warm temperate zone belongs to the East Asian monsoon region. The Huai River divides the Jianghuai area into two parts. The north part belongs to the warm temperate zone and is of humid and semi-humid monsoon climatic region. The south part is of subtropical humid monsoon climate. With the Yellow Sea to the east, the Jianghuai area is significantly impacted by the ocean. The solar radiation, atmospheric circulation, specific geographical location, and landform characteristics jointly make the area a place with a mild climate, distinct seasons, and significant monsoons. In terms of economic geography, the Jianghuai area is the transition area for the Yangtze River Delta economic belt and north China economic Belt. Therefore, the Jianghuai area is an "important" region not only for its local pollutant accumulation but the belt for pollutant 

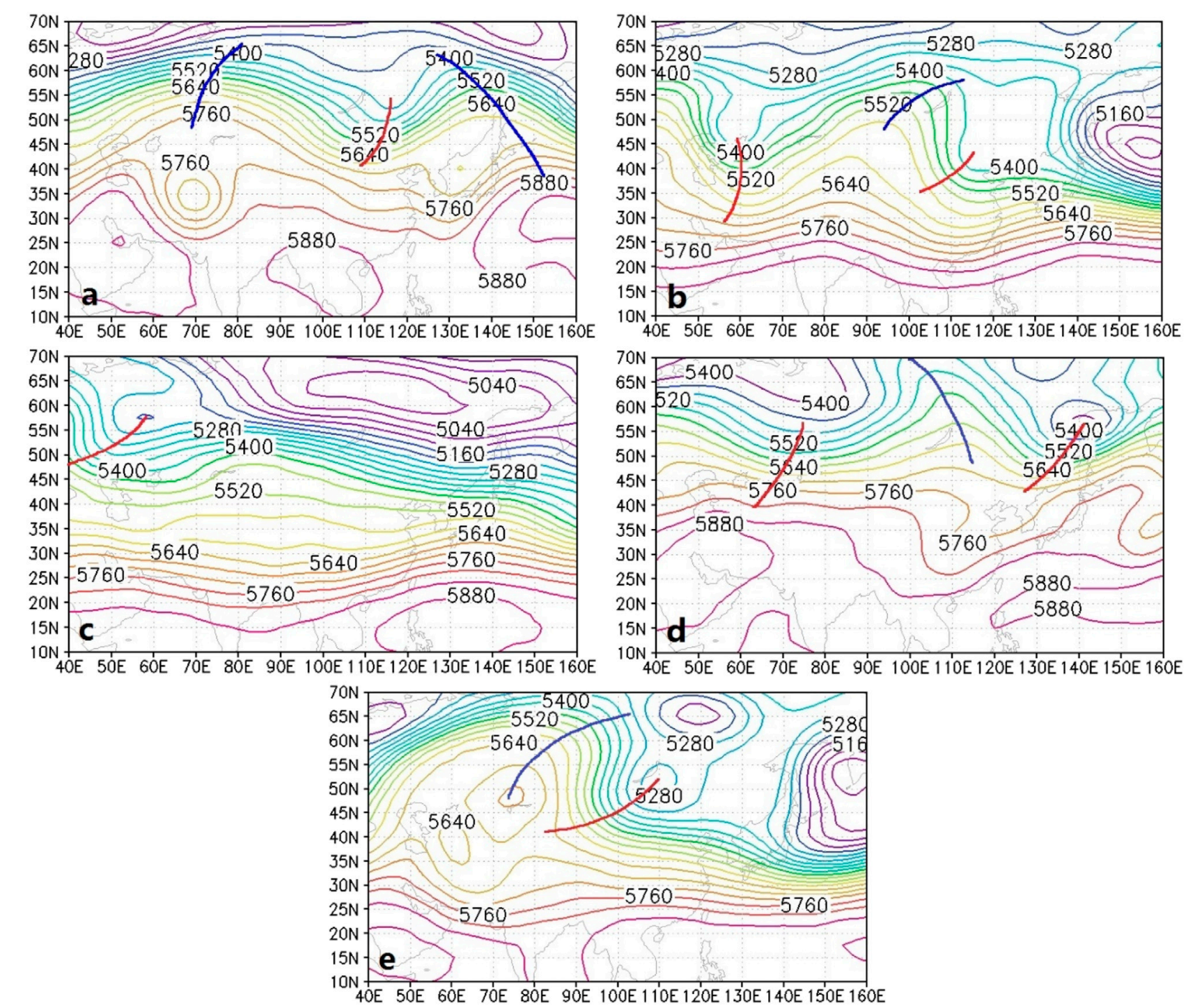

FIGURE 2 | Five 500-hPa circulation patterns favoring hazes in the Jianghuai area, China. They are (A) zonal circulation pattern, (B) two troughs and one ridge pattern, (C) one trough and one ridge pattern, (D) two ridges and one trough pattern, and (E) uniform dynamic geopotential height pattern.

transportation between North China and the Yangtze River Delta during the winter half of the year (often from October to next February).

Four primary meteorological stations (Xuzhou (XZ), Sheyang (SY), Fuyang (FY), Nanjing (NJ)) in Jianghuai Area and two (Shanghai (SH), Hangzhou (HZ)) in the Yangtze River Delta are selected for analysis. The red line (Figure 1) is used to analyze the wind field.

\section{Data and Method}

The sounding data from stations XZ, SY, FY, NJ, HZ, and SH are used in this study, with temperature profiles as the main variable. The sea-level pressure data from 709 stations of the China Meteorological Administration during the same period are also used (Figure 1). The Final Operational Global Analysis (FNL) data from the National Centers for
Environmental Prediction (NCEP) of the U.S. are used for cross-section wind and boundary layer height. The FNL data have a spatial resolution $1^{\circ} \times 1^{\circ}$.

\section{ATMOSPHERIC CIRCULATION AND BOUNDARY LAYERS \\ Circulation Characteristics Circulations on $500 \mathrm{hPa}$}

According to the synoptic conditions in the Jianghuai area over the past 30 years, the $500-\mathrm{hPa}$ circulations on haze days can be classified into five patterns (Figure 2). They are zonal circulation patterns, two troughs, and one ridge patterns, one trough and one ridge patterns, two ridges and one trough patterns, and uniform geopotential height patterns. 
TABLE 1 | 10 heavy haze episodes in the past few years.

\begin{tabular}{cccc}
\hline \multicolumn{2}{c}{ Date } & & Date \\
\hline 1 & Jan. 1-10, 2013 & 6 & Dec. 14-16, 2016 \\
2 & Dec. 1-10, 2013 & 7 & Dec. 18-20, 2016 \\
3 & Dec. 27-31, 2014 & 8 & Dec. 22-24, 2016 \\
4 & Jan. 3-4, 2015 & 9 & Dec. 21-24, 2017 \\
5 & Jan. 7-11, 2015 & 10 & Nov. 24-30, 2018
\end{tabular}

The zonal circulation pattern is featured in Figure 2A. The high levels $(700-500 \mathrm{hPa})$ of the Jianghuai area are controlled by the westerly. Occasionally, weak cold air mass from the polar vortex moves eastward along the westerly airflow, with its main part located to the north of $35^{\circ} \mathrm{N}$. Thus, the cold air mass has little impact on the Jianghuai area. When the cold air mass is in North China, the surface of the Jianghuai area is on the south of the weak cold high-pressure system and under weak high-pressure control, with a stable atmospheric stratification.

The two troughs and one ridge patterns are featured in Figure 2B. Sometimes, a small trough or ridge in front of a big ridge or trough invades North China and East China. When the cold air mass leaves, the surface pressure quickly weakens and the atmosphere becomes stable, which facilitates the accumulation of air pollutants. When the pollutants reach a certain level, haze may form, usually before the arrival of the next cold air mass. If the cold air mass cannot reach the south of $35^{\circ} \mathrm{N}$, the haze in the Jianghuai area will aggravate, and a persistent haze is likely to appear. If the cold air mass can reach $30^{\circ} \mathrm{N}$, the haze will dissipate. The duration of this kind of haze episode is related to the southernmost location the cold air mass can reach.

The one trough and one ridge patterns is featured shown in Figure 2C. The Jianghuai area is under the westerly in front of an inclined trough. For the surface pressure field, the main cold air mass is to the north of Xinjiang and the west of Lake Baikal. Occasionally, the weak cold air mass is detached from the main part and moves eastward along the westerly, affecting East China. Similar to the two troughs and one ridge pattern, the haze always appears in the latter half of the intermission between two cold air masses. The haze will dissipate when the new cold air mass arrives. For this pattern, the interval between the two cold air masses is relatively long.

The two ridges and one trough pattern is featured in Figure 2D. In most cases of this pattern, the study region is under a large but weak high-pressure system, extending across the Hetao region of Inner Mongolia to the Guanzhong District of Shaanxi Province and the west of it. The Jianghuai area is located under the weak pressure system, on the east of the high-pressure system. So, the atmosphere is stable, and the haze episode usually lasts for about 2 days. In the above four patterns on $500 \mathrm{hPa}$, if the northern trough is located further north and the southern trough is located further south, the mid-and high-latitude circulations would become zonal and haze could last for a longer time.

The uniform geopotential height pattern is featured in Figure 2E. The Jianghuai area is located north of the southern trough, and under the uniform geopotential height field in front of the northern trough. The Jianghuai area is under the weak pressure zone of a high-pressure system, with a stable atmospheric stratification; the situation can remain for a longer time.

We analyzed 10 heavy haze episodes in the past few years, there were westerly or northwesterly airflows on $500 \mathrm{hPa}$ (Table 1), and the wind direction turned to northwesterly in 6-12 $\mathrm{h}$ before the haze dissipated. For example, on Dec. 28, 2014, a westerly was maintained on $500 \mathrm{hPa}$ and turned into the northwesterly at 2:00 on Dec. 29. Eight hours later, the heavy haze in Jiangsu Province was reduced to light/moderate haze. At 14:00 on Dec. 30, the westerly prevailed on $500 \mathrm{hPa}$ over the Jianghuai area, and the circulation in the mid-latitude area was relatively zonal. The cold air mass was weak, and an equalized pressure field was likely formed. The static wind was conducive to the maintenance of heavy haze. However, at 2:00 on Dec. 31, the northwesterly appeared on $500 \mathrm{hPa}$. Visibility started to improve at 10:00 on Dec. 31, and the haze was finally mitigated. As the wind on $500 \mathrm{hPa}$ turned northwesterly, the downward transport of momentum could intensify the turbulence in the BL. The wind near the surface was then strengthened. Clearly, the 500-hPa wind direction change can indicate the mitigation of heavy haze, about 6-12 $\mathrm{h}$ in advance. Therefore, an analysis of high-level circulation on heavy haze days should help predict the evolution characteristics of the high levels $12 \mathrm{~h}$ before heavy haze.

During the large-area, persistent haze episode over the Jianghuai area in January 2013, the $500-\mathrm{hPa}$ circulation in the mid and high latitudes of Eurasia (Figure 2A) was zonal. There was a flat and weak trough over Jiangsu Province, while the main trough was over North China. The trough gradually moved eastward, and its south part moved more slowly. The southern branch of the trough over the Bay of Bengal was relatively shallow, and the frontal zone was to the south of $28^{\circ} \mathrm{N}$. The corresponding west-southwesterly wind was south of the Lower Reach of the Yangtze River. Such a weak weather system could not bring precipitation for the wet deposition of pollutants.

During the first 10 days of Dec. 2013, large-size fog and haze existed in the Jianghuai area. In this period, the area was controlled by the zonal circulation on $500 \mathrm{hPa}$, so the meridional wind was weak. The configuration of the upperand lower-level circulations facilitated the accumulation of pollutants in the BL, which was a typical synoptic condition for a persistent fog-haze episode.

\section{Synoptic Conditions Near the Surface}

Surface synoptic conditions on heavy haze days include equalized pressure (EQP), advancing edge of a cold front (ACF), base of high pressure $(\mathrm{BOH})$, backside of high pressure $(\mathrm{BAH})$, inverted trough (INT), and others. The EQP is featured in Figure 3A: the cold air mass is blocked in the north, and the Jianghuai area is controlled by an EQP field. The ACF is featured in Figure 3B: the cold air mass from the north strongly advances southward, and the Jianghuai area is controlled by the advancing edge of the cold front. The BOH is featured in Figure 3C: with the continental high moving southward slowly, the Jianghuai area is located at the base of the high. The BAH is featured in Figure 3D: as the continental high moves eastward, the Jianghuai area is on the 

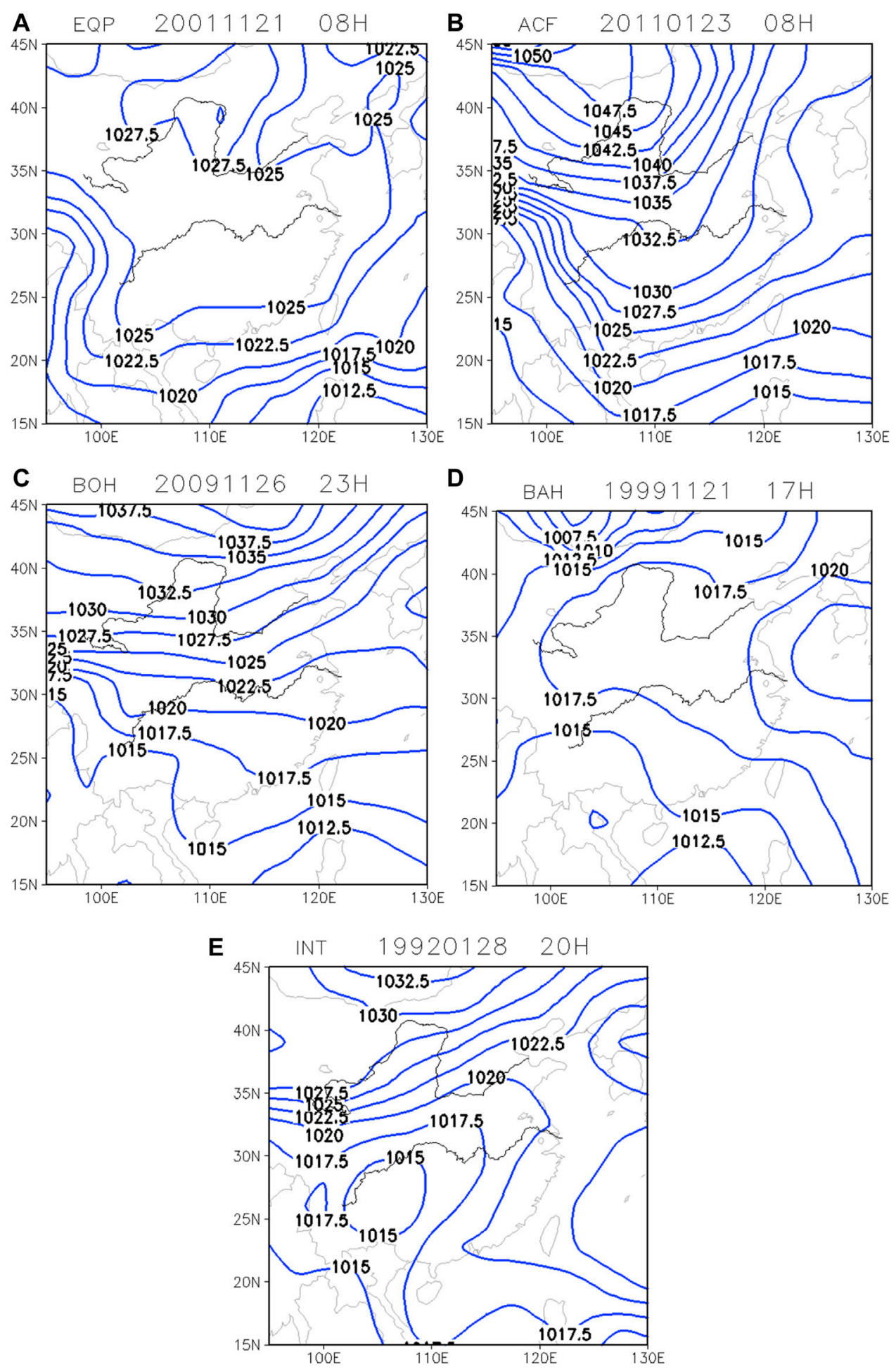

FIGURE 3|Surface conditions on heavy haze days. They are (A) equalized pressure field (EQP), (B) advancing edge of a cold front (ACF), (C) base of high pressure $(\mathrm{BOH})$, (D) backside of high pressure (BAH), and $(\mathbf{E})$ inverted trough (INT).

backside of the high that is over the sea. The INT is featured in Figure 3E: the Jianghuai area is affected by the weak highpressure system over the ocean in the early stage. Then, the weak high-pressure system recedes, and an inverted trough develops. The Jianghuai area is below the top of the inverted trough. In a persistent haze episode in our study area, the surface 


\section{A High pressure or equalized pressure field}

(typical steady situation in autumn and winter )

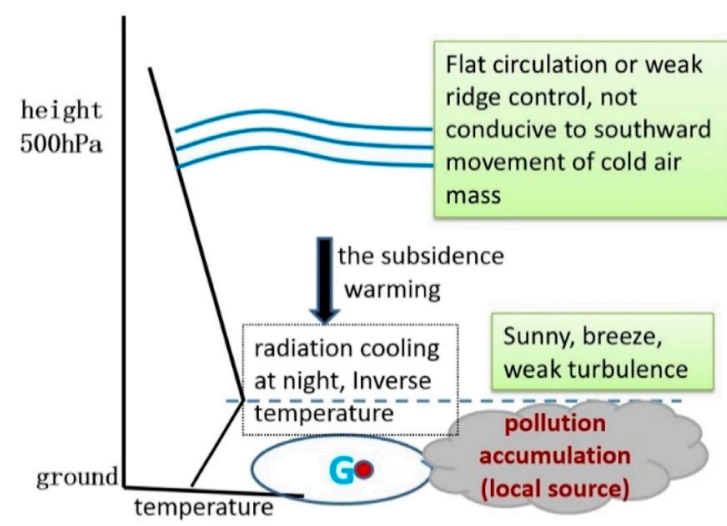

B

Cold air spreading south

( frontal passage, external transport )

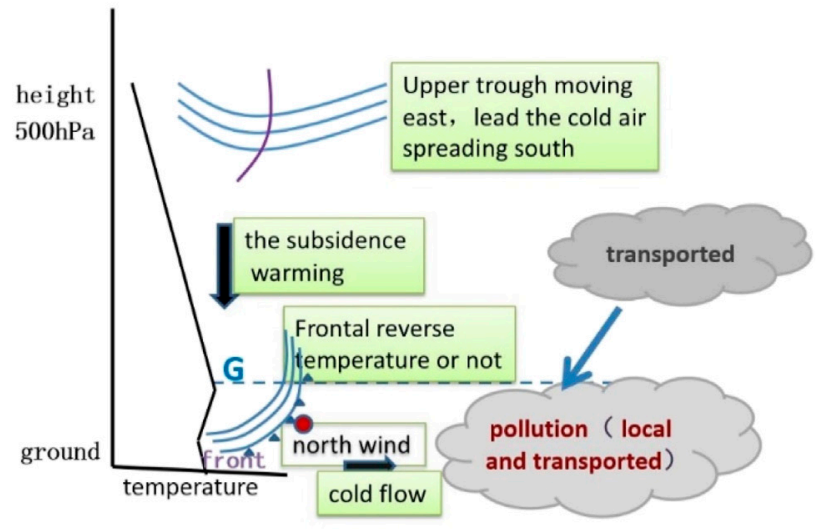

C The back of high pressure over the sea

(Usual accompanied by a inverted trough recesses east in the West)

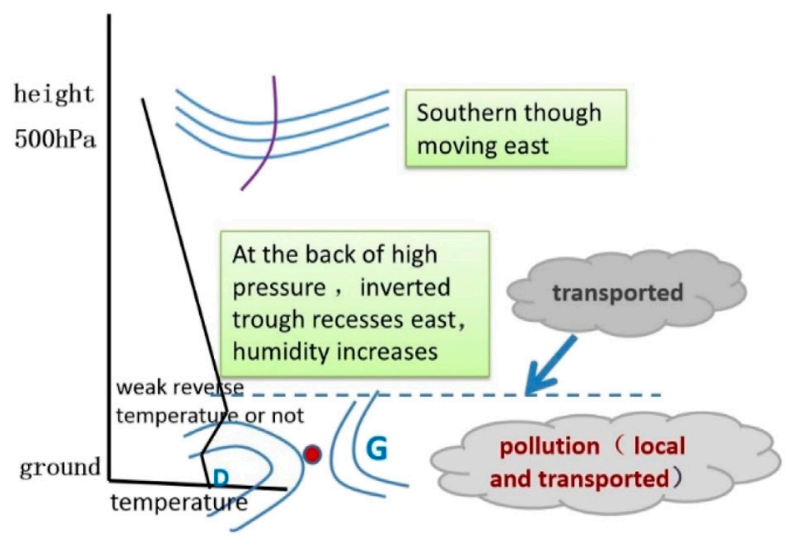

FIGURE 4 | Three types of high- and low-level circulations on fog-haze days in the Jianghuai area. (A) High pressure or equalized pressure field, (B) cold air spreading southward, and (C) The back of high pressure over the sea. condition is among the five surface types mentioned above (Peng et al., 2016).

During the large-size, persistent haze episode over the Jianghuai area in January 2013, the surface cold high ridge was in North and Northeast China. Jiangsu Province was under the equalized pressure at the front of the cold highpressure system, and an easterly prevailed in the lower levels. According to the change in the surface pressure field in January 2013, Jiangsu Province experienced two surface synoptic situations successively: the equalized pressure field at the front of the cold high-pressure system and the equalized pressure field at the back of the high-pressure system. Both were favorable for the fog-haze episode in Jiangsu Province.

Another example is the fog-haze episode in the Jianghuai area during the first 10 days of December 2013. The central and eastern parts of the surface pressure field were controlled by the equalized pressure. The pressure gradient was weak, so was the horizontal wind speed. The configuration of the upper- and lower-circulations was beneficial for the accumulation of pollutants in the $\mathrm{BL}$, which was a typical synoptic situation for a persistent fog-haze episode.

\section{Configuration of Upper- and Lower-Level Circulations}

Based on the above analyses, several circulation patterns favoring hazes are summarized, including the equalized high-pressure field, the cold air mass southward diffusion, and the backside of a high-pressure system over the ocean (Figure 4).

The high or equalized pressure pattern is shown in Figure 4A. The study area is under a high or equalized pressure system, the circulation at high levels is zonal, and the stratification is stable. It is sunny with strong radiative cooling at night. So, an inversion near the surface is likely to form. The surface wind speed is less than $3 \mathrm{~m} / \mathrm{s}$. The air pollutants mainly come from local accumulation. The diurnal variation of pollution is significant. The heavy pollution mainly occurs at night and in the morning and, the air quality will improve in the afternoon.

The cold air mass southward diffusion pattern is given in Figure 4B. The high-level trough guides the cold air mass to advance southward. The weather gradually turns to be overcast or rainy, the cloud cover increases, and precipitation may occur (mainly as light rain). The wind gradually turns to be northerly and becomes stronger. The local pollutants from previous days and the external pollutants transported from the north jointly cause heavy pollution. Its duration is related to the cold air's intensity and its southward speed. The affected area is closely related to the intensity of the cold air mass, and the relatively strong cold air mass can affect northern Zhejiang Province. Large-scale heavy pollution episodes often occur under this circulation pattern.

The backside of a high-pressure system over the ocean is the pattern featured in Figure 4C. On the west of the backside of the high-pressure system over the ocean, there is usually an inverted trough extending eastward. As the high-level trough moves eastward, the weather gradually turns to be overcast or rainy, and precipitation occurs. It is mainly light rain during the pollution days. The Jianghuai area is dominated by gradually strengthening southerly wind. The high relative humidity is 

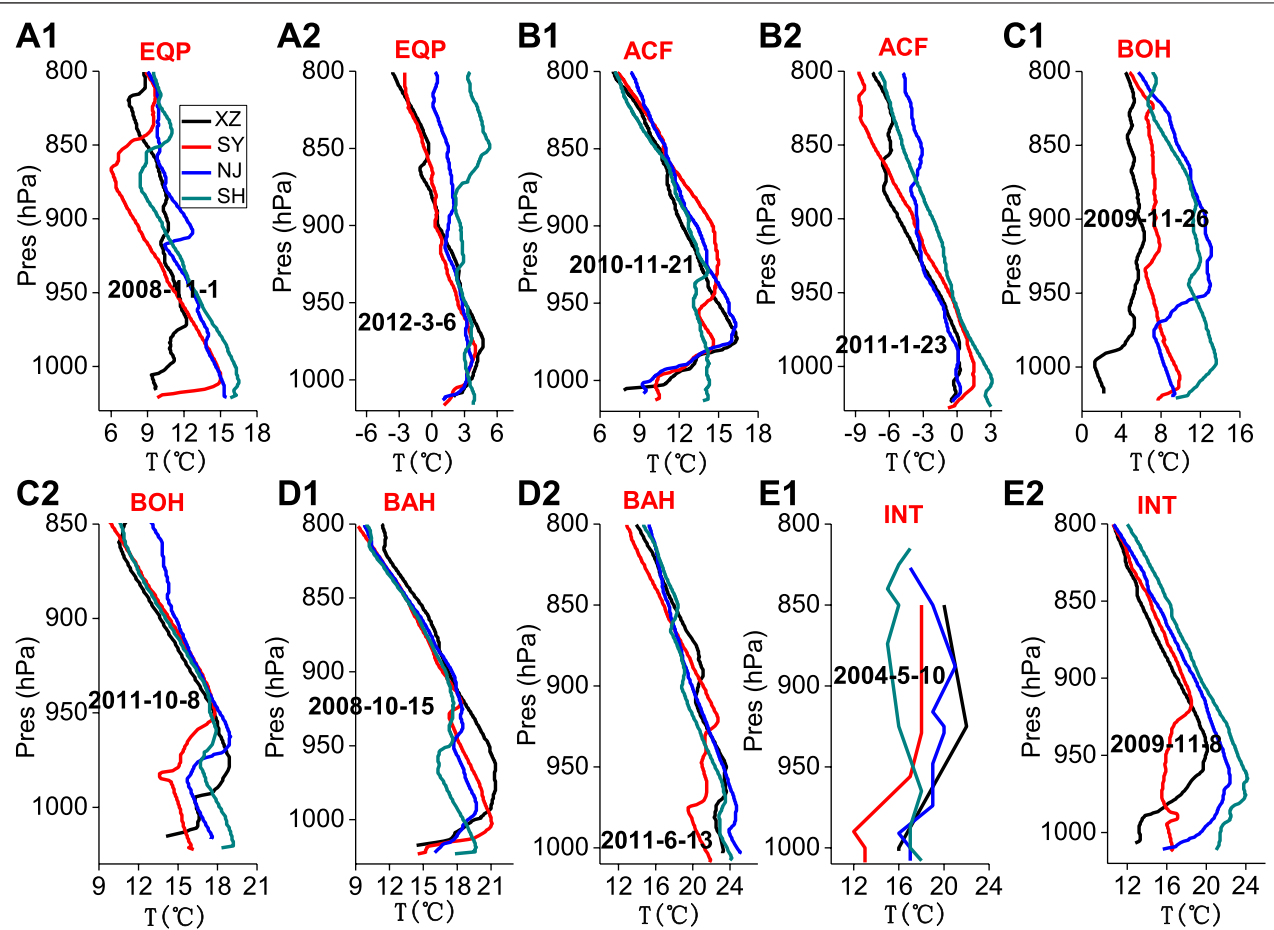

FIGURE 5 | Typical temperature profiles of regional heavy hazes at XZ, SY, NJ, and SH: (A) EQP, (B) ACF, (C) BOH, (D) BAH, and (E) INT. The $x$-axis is the temperature, and the $y$-axis is the pressure. After Peng et al. (2016).

conducive to the growth of pollutant particles, reduction of visibility, and aggravation of pollution. The heavy pollution is mainly due to local pollutants, though there is a certain amount of transported pollutants (mostly in southern Jiangsu and northern Zhejiang). With the further strengthening of the wind, the pollution is reduced.

\section{Boundary Layer Conditions in Jianghuai Area} Boundary Layer Structures During the Heavy Haze

BL condition is an important factor for the formation and maintenance of haze. According to the patterns of the surface synoptic conditions introduced in previous sections, the BL structures of different patterns are compared and analyzed. The heavy haze in EQP is characterized by an inversion or isothermal layer near the surface, and the inversion is mainly in a single layer or double layers (Figure 5A). The BL structure in ACF shows that the height of the inversion layer varies in different haze processes. The height of the inversion is very low, and the inversion mainly appears in a single layer. But the isothermal layer often appears at high levels (Figure 5B). In $\mathrm{BOH}$, there is a relatively large difference in the heights of the inversion layers among the stations, but the inversion appears below the height of $950 \mathrm{hPa}$ at all these stations, and multi-layer inversions are also found (Figure 5C). In BAH, the inversion or the isothermal layer mainly appears near the surface, and most of the cases exhibit multi-layer inversion structures (Figure 5D). On hazy days, the BL in INT is typically characterized by a thick inversion layer and a high bottom of the inversion (Figure 5E) (Peng et al., 2016).

\section{Dynamic Conditions in the Boundary Layer}

Under the long-lasting inversion near the surface, the atmosphere is relatively stable. Taking the spatiotemporal profiles of wind at stations Fuyang, Nanjing, Xuzhou, and Sheyang on Dec. 1-9, 2013 as an example (Figure 6), there were mainly southwesterly or southeasterly airflows below $500 \mathrm{~m}$ (inside the inversion layer) in Jiangsu Province and its surrounding areas. The wind was weaker than $3 \mathrm{~m} / \mathrm{s}$, with an average wind speed of $1-2 \mathrm{~m} / \mathrm{s}$. When the fog appeared, the wind speed was between 0.5 and $1.5 \mathrm{~m} / \mathrm{s}$. Therefore, the low wind speed was the dynamic condition for this fog-haze event, and a poor dynamic condition was not conducive to the vertical diffusion of air pollutants and water vapor. As a result, the fog-haze event was maintained for a long time.

To investigate the spatial variation characteristics of the $\mathrm{BL}$ in the Jianghuai area (line in Figure 1), we analyze the south-north cross-section of the wind field in the area using the NCEP reanalysis and observation data. Figure 7 displays the results of two typical cases that occurred at 0,800 on Dec. 19, 2016, and at 2000 on Dec. 23, 2016. When the wind was strong (Figure 7A), the wind speed near the surface was relatively uniform, without local recirculation. When the wind became weak (Figure 7B), local recirculation appeared in the Jianghuai area, that the wind directions in the layers $0-2 \mathrm{~km}$ were northerly wind, and the layer $2-5 \mathrm{~km}$ was southerly wind, which was greatly affected by other many factors, such as landform, urban heat island, the differences of underlying surfaces, and so on. 


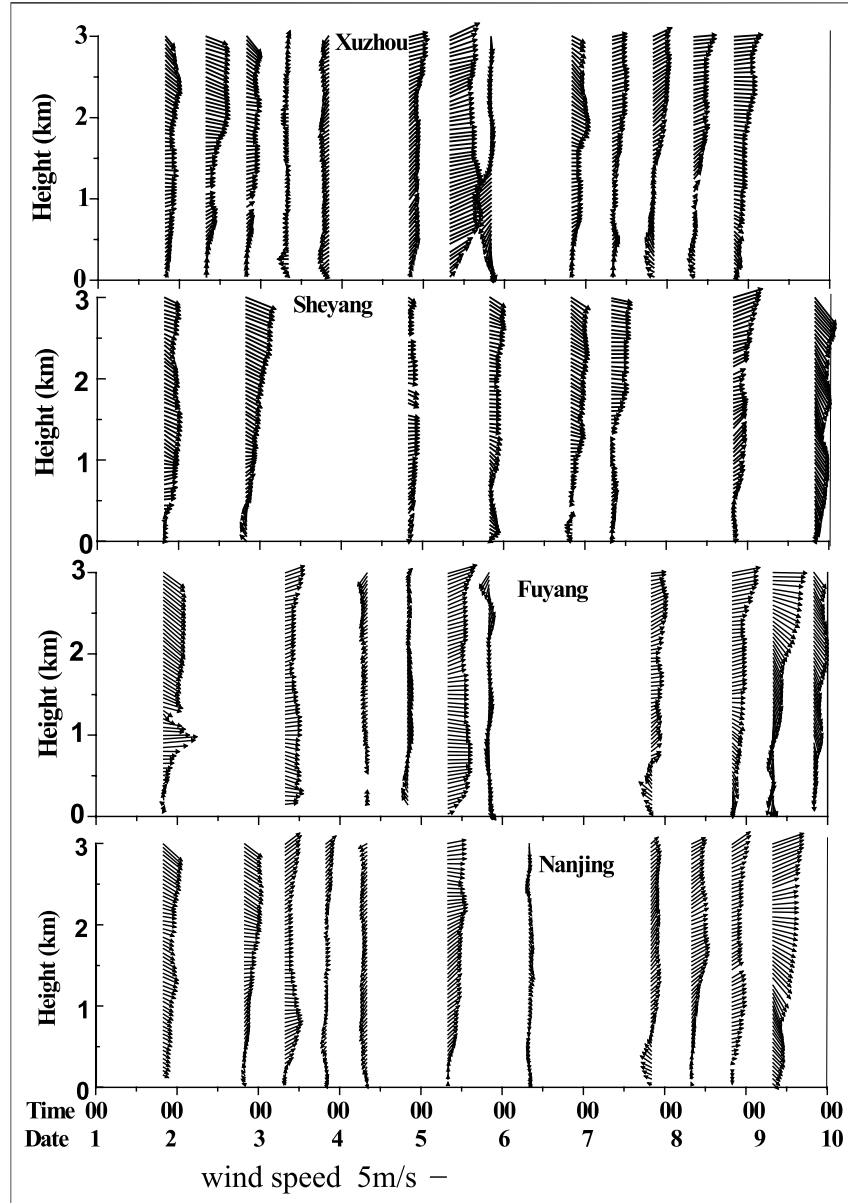

FIGURE 6 | Spatiotemporal cross-sections of the wind field at Xuzhou, Sheyang, Fuyang, and Nanjing during Dec. 1 and Dec. 9, 2013.

\section{ATMOSPHERIC BOUNDARY LAYER CONCEPTUAL MODEL AND ITS APPLICATIONS IN JIANGHUAI AREA}

\section{The Fixed Boundaries Over the North China Plain and the Pearl River Delta, China}

On the west of the Beijing-Tianjin-Hebei region (the North China Plain), there is the north-south-oriented Taihang Mountain. To the north of this region is the east-west-oriented Yanshan Mountain. When the stratification is stable or the southeasterly wind prevails, local pollutants and the pollutants transported from other places accumulate here, which can easily lead to heavy haze (Figure 8A). Unique landform and weather conditions play certain roles in the formation of haze in the Beijing-Tianjin-Hebei region (Ding et al., 2017). The blocking of the westerly by the Taihang Mountain is an important factor in the aggravation of air pollution in the central and southern parts of Hebei. When the prevailing wind is southerly, the wind will recirculate locally or climb over the Yanshan Mountain, which leads to decreased wind speed near the surface. It is unfavorable for the diffusion of pollutants, and the air pollutions are

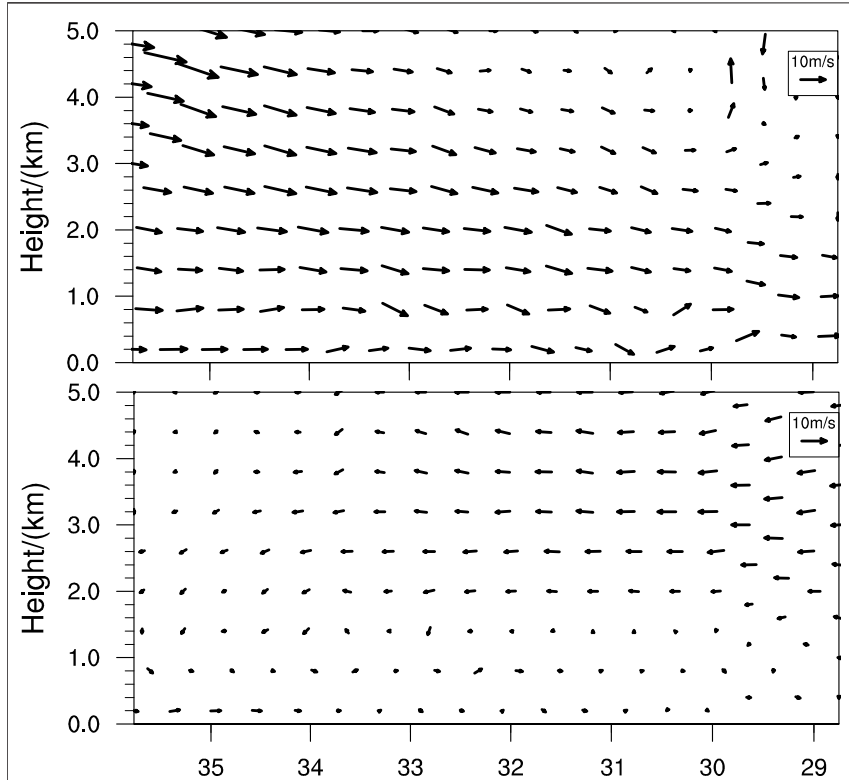

FIGURE 7 | The north-south cross-section (along with the red line in Figure 1) of the wind field in the Jianghuai area (top) 0,800 19-12-2016 (bottom) 2000 23-12- 2016.

aggravated in the cities in the central and southern BeijingTianjin-Hebei region (Jiang et al., 2015). There is a high-value band of pollutants from northeast to southwest in North China, with the highest center concentrated in front of the Taihang Mountain and the Yanshan Mountain, affecting Tangshan, Beijing, Tianjin, Langfang, Baoding, Shijiazhuang, Xingtai, and Handan (Meng et al., 2017). Li et al. (2015) also found that the remote transport rates of $\mathrm{PM}_{2.5}$ in Beijing, Tianjin, and Shijiazhuang were 58,54, and 39\%, respectively. During a heavy pollution event of Oct. 6-12, 2014 in the BeijingTianjin-Heibei region, the pollutants were transported from south to north, and the interregional transport greatly affected $\mathrm{PM}_{2.5}$ concentration in various regions ( $\mathrm{Li}$ et al., 2015). Influenced by the southerly, the region along the Taihang Mountain and the Shandong Peninsula-Bohai Bay area made great contributions to the summer air pollution. Especially, the high concentrations of $\mathrm{O}_{3}$ and $\mathrm{PM}_{2.5}$ in the summer over the Beijing-Tianjin-Hebei region had important impacts on the overall pollutant concentration increase in the background air pollution of North China (Xu et al., 2012).

Similar to the Beijing-Tianjin-Hebei region (the North China Plain), to the north of the Pearl River Delta (South China) is the south-east-oriented Nanling Mountains. When the stratification is stable or the southerly prevails, the pollutants are accumulated, and the accumulation may easily lead to heavy haze or air pollution (Figure 8B). Fan et al. (2006) reported that the unique geographical environment of the Pearl River Delta, which is surrounded by mountains on three sides, went against the transport and diffusion of air pollutants. The air pollutants from different cities and sources in the Pearl River Delta all have sizeable impacts on the air quality of the whole Pearl River Delta. 


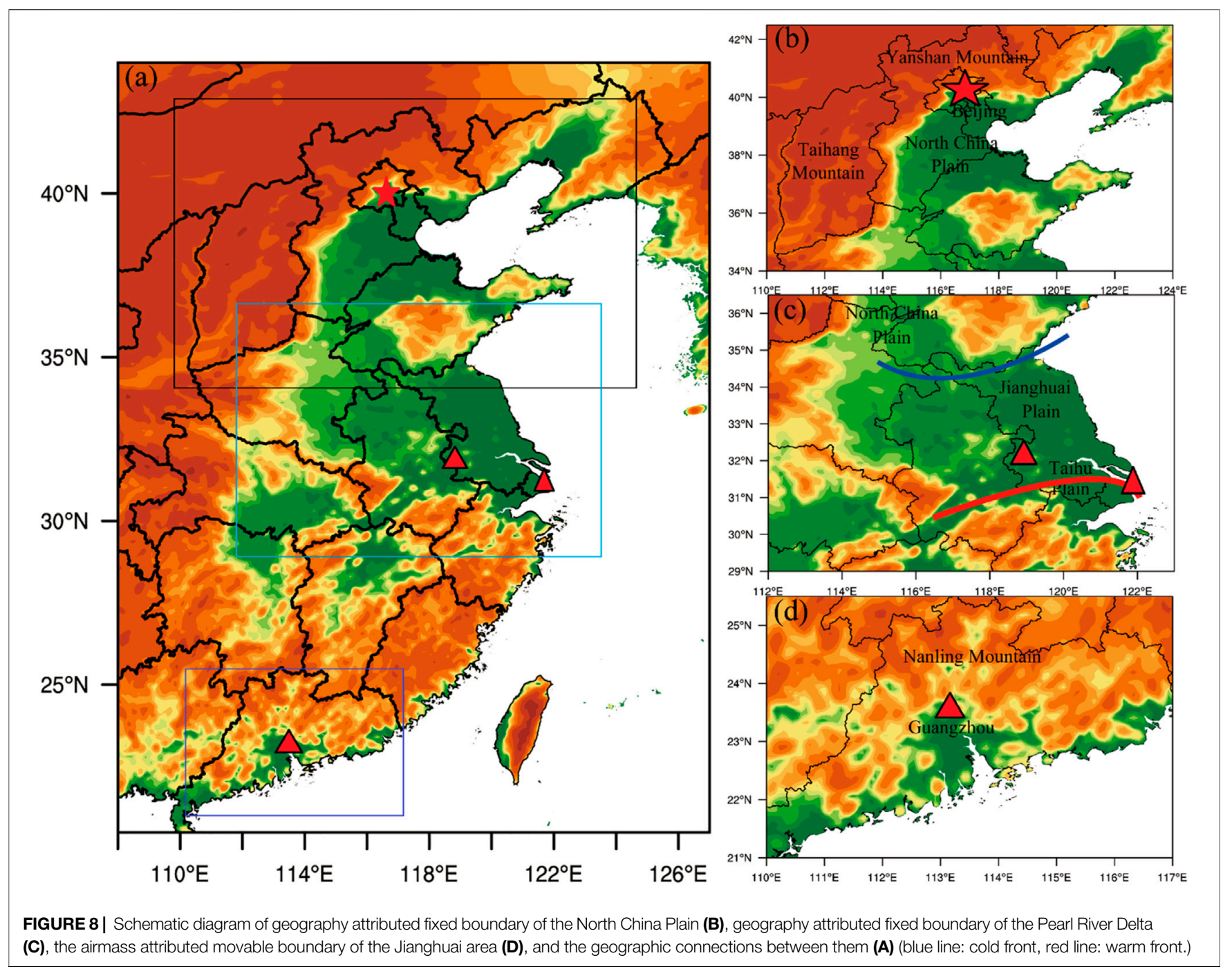

\section{The Movable Boundaries of the Jianghuai Area}

The landform and terrain of the Jianghuai area are rather different from those of the Beijing-Tianjin-Hebei region or the Pearl River Delta. There are no significant mountains around the area. From the south of the North China Plain to the Jianghuai Plain and the Taihu Plain, the terrain is relatively flat with a dense river network and better moisture conditions. The Yangtze River Delta in the south has a prosperous economy. Although there is no significant boundary, haze occurs more frequently from October to the following February (winter half of the year). As mentioned in Section 3.1, in the winter half of the year the cold dry northerly and the warm moist southeasterly influence this area alternately. The changes in the intensity and range of the cold and warm fronts can influence the changes in the range and boundary of a haze episode. Thus, a unique movable boundary forms as the changes of the cold and warm fronts in the Jianghuai area. We establish a movable boundary conceptual model in this study (Figure 8C).

\section{A Conceptual Model for Fog-Haze Episodes in the Winter Half of the Year Transport From Jianghuai Area to North China}

In the winter half of the year, when the Jianghuai area is affected by strong southerly or by significant precipitation, the air quality is good (Figure 9A shows the reasons). With a strong and long-lasting southerly, the pollutants can be transported to North China by the southerly, instead of accumulating in the Jianghuai area. Thus, the air quality in the study area can be excellent. Besides, significant precipitation can improve the air quality by wet scavenging.

\section{Strong Cold Air Mass Sweeping Over North China and East China}

In the winter half of the year when the Jianghuai area is influenced by strong cold air mass, the air quality may remain good in the Yangtze River Delta. Figure 9A explains the reasons. As long as the cold air mass is strong enough and the duration is long enough, the pollutants can be transported 


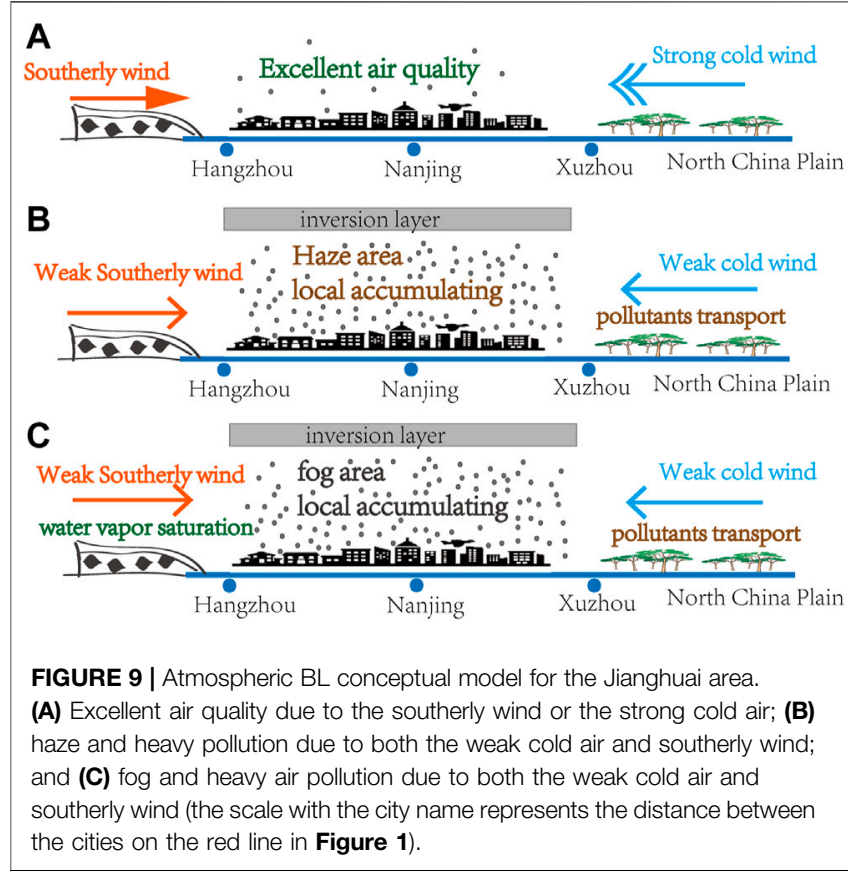

to the south of the Jianghuai area by the northerly, instead of accumulating in the Jianghuai area. The air quality may be excellent. The cold air affecting the Jianghuai area mainly has three paths: the easterly path, the westerly path, and the middle path. According to previous analyses, the influence of the easterly-path cold air mass on the Jianghuai area is greater than that of the westerly-path cold air mass; and the influence of the middle-path cold air mass is the weakest. When the strong wind sweeps over North China and East China, it can blow away pollutants and improve air quality in these regions (Gu et al., 2020).

\section{Local Accumulation and Pollutant Transportation From North China}

In the Jianghuai area, fog, haze, poor air quality, and high air pollution index often appear in the days with poor air diffusion capacities, such as calm wind and significant inversion (Liu et al., 2014a, Liu et al., 2014b). Figures 9B,C reveal that two situations may cause poor air quality and high air pollution in this area. First, when the cold air mass from the north is relatively weak, the thin cold air mass is pushed from north to south but sits under the deep warm moist air mass, forming a stable inversion in the BL. In this situation, the wind speed is relatively low; thus, the pollutants are transported by the weak cold air mass from North China to the Jianghuai area. Meanwhile, the local pollutants accumulate rapidly. Then, such conditions lead to the formation of the heavy air pollution. Second, when the intensity of the cold northerly is equal to that of the warm moist southerly, the wind speed in the $\mathrm{BL}$ is so low that it is difficult for horizontal diffusion of pollutants. The inversion layer is like a large-cap that prevents the pollutants from spreading upwards. Therefore, the pollutants keep accumulating in the Jianghuai area. This can lead to severe air pollution. In the above two situations, the front edge of the cold or warm air mass is the horizontal boundary when the wind speed is less than $3 \mathrm{~m} / \mathrm{s}$. The upper boundary and horizontal boundary are the inversion layer and downward flow or are the wind shear zone between the southerly and northerly. The heavy pollution episodes are caused by both pollutant transportation and local emissions. These two situations often appear in the winter half of the year. Once there is a high humidity condition, it is easy to form dense fog over a large area, which will cause more serious problems for both traffic and public health.

\section{CONCLUSION}

Based on the analyses of atmospheric circulation characteristics and $\mathrm{BL}$ conditions in the Jianghuai area, a movable boundary conceptual model is established. The model can explain the causes of frequent haze and the change in the environmental air quality in the study area.

The changes in the intensity and range of the cold and warm fronts in the winter half of the year lead to unique movable (fluid) boundary characteristics in the Jianghuai area, which affect the range and boundary of the haze in this area. Based on these characteristics, the movable boundary conceptual model in the Jianghuai area is established. The main features of the conceptual model are as follows:

1) With a strong southerly, the pollutants can be spread to North China. Thus, the air quality in the Jianghuai area can be excellent, and significant precipitation can also improve the air quality by wet scavenging.

2) Under the influence of strong cold air mass, the air quality of the Jianghuai area is excellent. The influence of the easterlypath cold air mass on this area is greater than that of the westerly-path cold air mass, and the influence of the middlepath cold air mass is the weakest.

3) The thin cold air mass sits under the deep warm moist air mass, and a stable inversion is thus formed. The pollutants from both local accumulation and remote transportation can jointly cause heavy air pollution in the study area.

4) When the intensity of the cold northerly is equal to that of the warm moist southerly, the pollutants from local emissions and from North China can keep on accumulating in the Jianghuai area, which may lead to more severe air pollution.

Under the situations of (3) and (4), the front edge of cold/ warm air mass (wind speed less than $3 \mathrm{~m} / \mathrm{s}$ ) is the horizontal boundary. The upper boundaries are the inversion layer or downward flow, or the wind shear zone between the southerly and northerly. The heavy pollution episodes are caused by both pollutant transportation and local emissions. Combined with the results of the numerical weather forecast, this model has been applied to guiding the air quality weather forecasting and all of the air pollutant processes can be accurately predicted. Although this conceptual model needs to be tested and verified by more cases, it will help analyze the atmospheric diffusion 
capacity in the Jianghuai area. It can provide the forecast and early warning of airflow stagnation area or fog-haze.

\section{DATA AVAILABILITY STATEMENT}

The original contributions presented in the study are included in the article/Supplementary Material, further inquiries can be directed to the corresponding authors.

\section{AUTHOR CONTRIBUTIONS}

Conceptualization, DL; methodology, WY and ML; software, JQ and ZW; validation, DL and WY; formal analysis, HP; investigation, MC; resources, DL; data curation, WY; writing-original draft preparation, DL and WY; writing-review and editing, DL; visualization, JQ and HP;

\section{REFERENCES}

Chen, S., Liu, D., Kang, Z., Shi, Y., and Liu, M. (2021). Anomalous Atmospheric Circulation Associated with the Extremely Persistent Dense Fog Events over Eastern China in the Late Autumn of 2018. Atmosphere 12 (1), 111. doi:10.3390/atmos12010111

Dai, J., Wang, X., Dai, W., and Chang, M. (2019). The Impact of Inhomogeneous Urban Canopy Parameters on Meteorological Conditions and Implication for Air Quality in the Pearl River Delta Region. Urban Clim. 29, 100494. doi:10.1016/j.uclim.2019.100494

Dai, Z., Liu, D., Yu, K., Cao, L., and Jiang, Y. (2020). Meteorological Variables and Synoptic Patterns Associated with Air Pollutions in Eastern China during 20132018. Int. J. Environ. Res. Public Health 17 (7), 2528. doi:10.3390/ ijerph17072528

Ding, Y., and Liu, Y. (2014). Analysis of Long-Term Variations of Fog and Haze in China in Recent 50 Years and Their Relations with Atmospheric Humidity. Sci. China Earth Sci. 57, 36-46. doi:10.1007/s11430-013-4792-1

Ding, Y., Wu, P., Liu, Y., and Song, Y. (2017). Environmental and Dynamic Conditions for the Occurrence of Persistent Haze Events in North China. Engineering 3, 266-271. doi:10.1016/j.eng.2017.01.009

Fan, S., Wang, A., Fan, Q., Liu, J., and Wang, B. (2005). Atmospheric Boundary Layer Conceptual Model of the Pearl River Delta and its Application. J. Trop. Meteorology 21, 286-292.

Fan, S., Wang, A., Fan, Q., Liu, J., and Wang, B. (2006). Atmospheric Boundary Layer Features of Pearl River Delta and its Conception Model. China Environ. Sci. 26, 4-6.

Gu, P., Qian, J., Liu, D., Wang, K., Dai, Z., Peng, X., et al. (2020). Cold Fronts Transport Features of North China Pollutant over Jiangsu Province, China. Atmos. Pollut. Res. 11 (10), 1785-1796. doi:10.1016/j.apr.2020.07.015

Jiang, Y., Zhu, R., Zhu, K., and Li, Z. (2015). Numerical Simulation on the Air Pollution Potential in the Severe Air Pollution Episodes in the Beijing-TianjinHebei Region. Acta Scientiae Circumstantiae 35, 2681-2692.

Li, S., Cheng, N., Xu, J., Nie, L., Meng, F., Pan, T., et al. (2015). Spatial and Temporal Distributions and Source Simulation of $\mathrm{PM}_{2.5}$ in the Beijing-TianjinHebei Region in 2014. China Environ. Sci. 35, 2908-2916.

Li, W., Liu, X., Zhang, Y., Sun, K., Wu, Y., Xue, R., et al. (2018). Characteristics and Formation Mechanism of Regional Haze Episodes in the Pearl River Delta of China. J. Environ. Sci. 63, 236-249. doi:10.1016/j.jes.2017.03.018

Li, M., Wang, T., Xie, M., Li, S., Zhuang, B., Huang, X., et al. (2019). Formation and Evolution Mechanisms for Two Extreme Haze Episodes in the Yangtze River Delta Region of China during winter 2016. J. Geophys. Res. Atmos. 124, 3607-3623. doi:10.1029/2019jd030535

Li, M., Wang, L., Liu, J., Gao, W., Song, T., Sun, Y., et al. (2020). Exploring the Regional Pollution Characteristics and Meteorological Formation Mechanism supervision, DL and WY; project administration, DL; funding acquisition, DL. All authors have read and agreed to the published version of the manuscript.

\section{FUNDING}

This work was jointly supported by the National Natural Science Foundation of China (42075063), Open fund by Jiangsu Key Laboratory of Atmospheric Environment Monitoring and Pollution Control (KHK2005), and the Jiangsu Meteorological Bureau General project (KZ201902).

\section{ACKNOWLEDGMENTS}

Thanks to the Chinese Ministry of Environmental Protection for providing the environmental monitoring data.

of PM2.5 in North China during 2013-2017. Environ. Int. 134, 105283. doi:10.1016/j.envint.2019.105283

Liang, D., Wang, H., Zhou, L., An, J., Tang, L., Lu, C., et al. (2017). Regional and Local New Particle Formation Events Observed in the Yangtze River Delta Region, China. J. Geophys. Res. Atmos. 122 (4), 2016JD026030. doi:10.1002/2016JD026030

Liu, D., Zhang, J., Wu, X., Yan, W., Zhou, B., and Xie, Z. (2014a). Characteristics and Sources of Atmospheric Pollutants during a Fog-Haze Process in Huai'an. Trans. Atmos. Sci. 37, 484-492. doi:10.13878/j.cnki.dqkxxb.20121007001

Liu, D., Pu, M., Yan, W., and Xie, Z. (2014b). Study on the Formation and the Cause of the Fog-Haze Transformation in the Lower Reaches of Huaihe River. China Environ. Sci. 34, 1622-1632.

Liu, D., Yan, W., Kang, Z., Liu, A., and Zhu, Y. (2018a). Boundary-layer Features and Regional Transport Process of an Extreme Haze Pollution Event in Nanjing, China. Atmos. Pollut. Res. 9 (6), 1088-1099. doi:10.1016/ j.apr.2018.04.009

Liu, D., Su, Y., Peng, H., Yan, W., Li, Y., Liu, X., et al. (2018b). Size Distributions of Water-Soluble Inorganic Ions in Atmospheric Aerosols during the Meiyu Period on the North Shore of Taihu Lake, China. Aerosol. Air Qual. Res. 18 (12), 2997-3008. doi:10.4209/aaqr.2018.04.0123

Liu, C., Hua, C., Zhang, H., Zhang, B., Wang, G., Zhu, W., et al. (2019a). A Severe Fog-Haze Episode in Beijing-Tianjin-Hebei Region: Characteristics, Sources and Impacts of Boundary Layer Structure. Atmos. Pollut. Res. 10 (4), 1190-1202. doi:10.1016/j.apr.2019.02.002

Liu, C., Wang, T. J., Chen, P. L., Li, M. M., Zhao, M., Zhao, K., et al. (2019b). Effects of Aerosols on the Precipitation of Convective Clouds: A Case Study in the Yangtze River Delta of China. J. Geophys. Res. Atmos. 124 (14), 7868-7885. doi:10.1029/2018jd029924

Lohou, F., Kalthoff, N., Adler, B., Babić, K., Dione, C., Lothon, M., et al. (2020). Conceptual Model of Diurnal Cycle of Low-Level Stratiform Clouds over Southern West Africa. Atmos. Chem. Phys. 20 (4), 2263-2275. doi:10.5194/acp-20-2263-2020

Lv, Z., Wei, W., Cheng, S., Han, X., and Wang, X. (2020). Meteorological Characteristics within Boundary Layer and its Influence on PM2.5 Pollution in Six Cities of North China Based on WRF-Chem. Atmos. Environ. 228, 117417. doi:10.1016/j.atmosenv.2020.117417

Meng, K., Cheng, X., Xu, X., Qu, X., Ma, C., Zhao, Y., et al. (2017). Spatial-temporal Variations of Pollutant Emission Sources Inversed by Adaptive Nudging Scheme over Beijing-Tianjin-Hebei Region Based on the CMAQ Model. Acta Scientiae Circumstantiae 37, 52-60.

$\mathrm{Mu}$, M., and Zhang, R. (2014). Addressing the Issue of Fog and Haze: A Promising Perspective from Meteorological Science and Technology. Sci. China Earth Sci. 57, 1-2. doi:10.1007/s11430-013-4791-2

Pal, S. (2016). On the Factors Governing Water Vapor Turbulence Mixing in the Convective Boundary Layer over Land: Concept and Data Analysis Technique Using Ground-Based Lidar Measurements. Sci. Total Environ. 554-555, 17-25. doi:10.1016/j.scitotenv.2016.02.147 
Peng, H., Liu, D., Zhou, B., Su, Y., Wu, J., Shen, H., et al. (2016). Boundary-Layer Characteristics of Persistent Regional Haze Events and Heavy Haze Days in Eastern China. Adv. Meteorol. 2016, 1-23. doi:10.1155/2016/6950154

Shen, L., Wang, H., Kong, X., Zhang, C., Shi, S., and Zhu, B. (2021a). Characterization of Black Carbon Aerosol in the Yangtze River Delta, China: Seasonal Variation and Source Apportionment. Atmos. Pollut. Res. 12 (1), 195-209. doi:10.1016/j.apr.2020.08.035

Shen, L., Wang, H., Cheng, M., Ji, D., Liu, Z., Wang, L., et al. (2021b). Chemical Composition, Water Content and Size Distribution of Aerosols during Different Development Stages of Regional Haze Episodes over the North China Plain. Atmos. Environ. 245, 118020. doi:10.1016/j.atmosenv.2020.118020

Shi, C., Nduka, I. C., Yang, Y., Huang, Y., Yao, R., Zhang, H., et al. (2020). Characteristics and Meteorological Mechanisms of Transboundary Air Pollution in a Persistent Heavy PM2.5 Pollution Episode in Central-East China. Atmos. Environ. 223, 117239. doi:10.1016/j.atmosenv.2019.117239

Sun, X., Zhao, T., Liu, D., Gong, S., Xu, J., and Ma, X. (2020). Quantifying the Influences of PM2.5 and Relative Humidity on Change of Atmospheric Visibility over Recent Winters in an Urban Area of East China. Atmosphere 11, 461. doi:10.3390/atmos11050461

Toledo, F., Haeffelin, M., Wærsted, E., and Dupont, J.-C. (2021). A New Conceptual Model for Adiabatic Fog. Atmos. Chem. Phys. 21 (17), 13099-13117. doi:10.5194/acp-21-13099-2021

Wang, H., Zhu, B., Shen, L., Xu, H., An, J., Pan, C., et al. (2016). Regional Characteristics of Air Pollutants during Heavy Haze Events in the Yangtze River Delta, China. Aerosol Air Qual. Res. 16 (9), 2159-2171. doi:10.4209/aaqr.2015.09.0551

Wang, H., Zhang, Z., Liu, D., Zhu, Y., Zhang, X., and Yuan, C. (2020). Study on a Large-Scale Persistent Strong Dense Fog Event in Central and Eastern China. Adv. Meteorol. 2020, 8872334. doi:10.1155/2020/8872334

Wang, H., Pei, Y., Yin, Y., Shen, L., Chen, K., Shi, Z., et al. (2021). Observational Evidence of Lightning-Generated Ultrafine Aerosols. Geophys. Res. Lett. 48 (14), e2021GL093771. doi:10.1029/2021gl093771

Wojtal, P., Halla, J. D., and McLaren, R. (2011). Pseudo Steady States of HONO Measured in the Nocturnal marine Boundary Layer: a Conceptual Model for HONO Formation on Aqueous Surfaces. Atmos. Chem. Phys. 11 (7), 3243-3261. doi:10.5194/acp-11-3243-2011

Wu, M., Wu, D., Fan, Q., Wang, B. M., Li, H. W., and Fan, S. J. (2013). Observational Studies of the Meteorological Characteristics Associated with Poor Air Quality over the Pearl River Delta in China. Atmos. Chem. Phys. 13 (21), 10755-10766. doi:10.5194/acp-13-10755-2013

Wu, P., Ding, Y., and Liu, Y. (2017). Atmospheric Circulation and Dynamic Mechanism for Persistent Haze Events in the Beijing-Tianjin-Hebei Region. Adv. Atmos. Sci. 34 (4), 429-440. doi:10.1007/s00376-016-6158-z
Xie, M., Zhan, C., Zhan, Y., Shi, J., Luo, Y., Zhang, M., et al. (2021). Spatiotemporal Variability of Air Stagnation and its Relation to Summertime Ozone in the Yangtze River Delta of China. Front. Environ. Sci. 9, 517. doi:10.3389/ fenvs.2021.783524

Xu, X., Liu, Z., Gao, W., Wang, Y., and Xin, J. (2012). Changes in Atmospheric Background Pollution during Summer in the Beijing-Tianjin-Hebei Region after the 2008 Olympic Games in China. Res. Environ. Sci. 9, 959-967.

Yu, X., Ma, J., An, J., Yuan, L., Zhu, B., Liu, D., et al. (2016). Impacts of Meteorological Condition and Aerosol Chemical Compositions on Visibility Impairment in Nanjing, China. J. Clean. Prod. 131, 112-120. doi:10.1016/ j.jclepro.2016.05.067

Zhang, R., Qiang, L., and Zhang, R. (2014). Meteorological Conditions for the Persistent Severe Fog and Haze Event over Eastern China in January 2013. Sci. China Earth Sci. 57, 26-35. doi:10.1007/s11430-013-4774-3

Zhang, L., Zhao, T., Gong, S., Kong, S., Tang, L., Liu, D., et al. (2018). Updated Emission Inventories of Power Plants in Simulating Air Quality during Haze Periods over East China. Atmos. Chem. Phys. 18 (3), 2065-2079. doi:10.5194/ acp-18-2065-2018

Zhou, B., Liu, D., and Yan, W. (2021). A Simple New Method for Calculating Precipitation Scavenging Effect on Particulate Matter: Based on Five-Year Data in Eastern China. Atmosphere 12 (6), 759. doi:10.3390/atmos12060759

Zong, P., Zhu, Y., Wang, H., and Liu, D. (2020). WRF-chem Simulation of Winter Visibility in Jiangsu, China, and the Application of a Neural Network Algorithm. Atmosphere 11 (5), 520. doi:10.3390/atmos11050520

Conflict of Interest: The authors declare that the research was conducted in the absence of any commercial or financial relationships that could be construed as a potential conflict of interest.

Publisher's Note: All claims expressed in this article are solely those of the authors and do not necessarily represent those of their affiliated organizations, or those of the publisher, the editors and the reviewers. Any product that may be evaluated in this article, or claim that may be made by its manufacturer, is not guaranteed or endorsed by the publisher.

Copyright (C) 2021 Liu, Yan, Qian, Liu, Wang, Cheng and Peng. This is an openaccess article distributed under the terms of the Creative Commons Attribution License (CC BY). The use, distribution or reproduction in other forums is permitted, provided the original author(s) and the copyright owner(s) are credited and that the original publication in this journal is cited, in accordance with accepted academic practice. No use, distribution or reproduction is permitted which does not comply with these terms. 